\title{
Problems of Medical Confidentiality While Using Electronic Documents in Psychiatric Practice
}

\author{
Nazim Y. Orudjev, Olga V. Poplavskaya, Lev B. \\ Lempert \\ Dept. of Psychyatry, Volgograd State Medical University, \\ Volgograd, Russia \\ orudjev38@mail.ru, poplavok9@rambler.ru, \\ faust807@mail.ru
}

\author{
Natalia A. Salnikova \\ Dept. of Information System, Volgograd Branch of the \\ Russian Presidential Academy of National Economy and \\ Public Administration, Volgograd, Russia \\ ns3112@mail.ru
}

\begin{abstract}
The article discusses the benefits of information technology in the health sector, particularly in psychiatric practice. The necessity of regulating access to electronic medical record is closely related to the problem of medical confidentiality. A case from the practice of outpatient psychiatric services related to the medical confidentiality problem when dealing with appeals of citizens and public authorities, analyzed by the case study method.
\end{abstract}

Keywords-medical secrecy, mental health services, electronic forms of medical records, electronic medical history, information and communication technologies, confidentiality.

\section{INTRODUCTION}

Modern information and communication technologies (ICT) have an increasing influence on the overall development of medicine, the quality of medical services and the health system efficiency. Computerization is an essential tool for solving problems of increasing the availability and quality of medical care, by taking into account key indicators according to the and medical assistance standards and protocols, centralization of information resources for decision support systems, and continuing medical education. Information infrastructure, provide more efficient processing and use of medical resources as well as secure data exchange. In recent years, the need for modern information technology in health care, especially with regard to establishing a system of differential medical diagnosis is not in doubt [1,2]. Special attention is paid for systems focused on improving the quality of medical services [3]. The software implementation model of the medical knowledge representation is the most relevant approach to differential diagnosis medical expert system development $[4,5]$.

Currently, most developed countries have adopted and implemented national programs in the e-health protection field. The use of modern ICT in this area only begins in Russia, information and communication infrastructure for the medical needs have been created [6].

Development of information medicine is uneven; psychiatry lags behind of internist clinic in this area. Static and dynamic evaluation of the patient's condition in psychiatric practice as well as prognosis of treatment effectiveness are based mainly on verbalized data facts of inspection and surveillance, obtained directly in contact with the patient when a particular subjective evaluation of this kind of information is inevitable. That is why possibilities of informational support for structuring, processing and analysis of semantic data provided by automated information systems are essential in that field of scientific and practical medicine and its value for broad application still not fully estimated.

Automated systems of electronic medical record in psychiatry are used only in a few institutions, due to the high cost of the project $[7,8,9]$.

\section{THE BENEFITS OF PSYCHIATRIC SERVICES INFORMATIZATION}

The results of combining all the regional mental illness institutions into a single facility in the Astrakhan region and the introduction of ICT in its work demonstrated improved communication and continuity of the structural units: the possibility of consulting the most difficult patients by medical commission and psychiatric examination of patients via videoconference on-line; opportunity to obtain all necessary information about the patient, as well as records of patient visits by rural district psychiatrists; real-time decision of validity and effectiveness of prescribing to patients; possibility of hospitalization as soon as possible in case of urgency [10].

Today, the vast majority of primary information stored as printed or write documents or in the form of records and graphic images not available for automated analysis. It is difficult to find a specific piece of information, for example, data from a study on computed tomography, or to establish the fact that this study was done, when using paper medical records. Doctors turn pages of case report, searching for relevant documents or information. Availability of medical records in the computer memory allows the user to obtain the data in a well-structured form, which greatly facilitates the extraction of the necessary information. The data, once trapped in the computer may be used in a variety of documents without retyping, and may be presented in a new forms, never been used in manual systems. Graphical presentation, description of temporal relationship between clinical events and the correlation between the parameter values is possible. The results of additional methods of investigation (electroencephalography, X-ray imaging, CT, MRT, even photos of patients and their drawings as well as audio and video can be stored in electronic form [11]. Thus, while ensuring conditions of safety and permanence, reliability and protection of electronic information the problem of important 
for diagnosis and personalized therapy health investigation data loss or damaging, can be solved.

A compulsory component of mental illness facilities informatization will be the introduction of electronic document management system reducing non-core activities of health professionals for completing certificates, various statistical forms and other numerous documents. It will also stop providing of the referral and statements to patients in a sealed envelope, which is done to prevent psychic trauma of patient who can experience severe shock and make rash actions (suicide, show aggressive tendencies, etc.) had become familiar to his diagnosis. As a rule, patients and their relatives are able to read the contents of the envelope and decipher the ICD-10 diagnosis code using the Internet, receiving information about the disease not from a doctor, but from unskilled online community (forums, social networks, etc.). The ability for psychiatrists to receive and transmit all necessary patient information through electronic documents will protect the patient from harmful information.

The process of informatization has also advantages for patients: all the decisions and actions of the doctor became documented and personal responsibility for their adoption will not be blurred due to illegible handwriting or missing analyzes. In an emergency physician of any public hospital will be able to get the full information about the health of the patient, referring to electronic medical records.

The allocation of access rights to electronic medical records should be based on the same requirements that apply to paper documents. When transmitting information it is necessary to satisfy the requirements of the law, as well as immutability, and the accuracy of personally identifiable records, which must be protected by electronic digital signature of the author or the head of the institution.

\section{THE RIGHTS AND ORGANIZATION OF ACCESS TO ELECTRONIC MEDICAL RECORDS}

The well-being of not only the patients, but also society as a whole depends largely on the ensuring of the law in the sphere of security and civil rights protection of citizens with mental illness, the duties integrity by officials of institutions and organizations involved in helping people with mental disorders

According to the Law of the Russian Federation dated July 2, 1992 No. 3185-1 «On psychiatric care and guarantees of citizens' rights in its provision», Article 5, second part (the Act), all persons suffering from mental disorders are entitled to receive information on the nature of their mental disorders, and the methods of treatment in the form accessible to them, and taking into account their mental state in the course of mental health care provision [12].

However, medical records often contain information, knowledge of which by patients may have adverse consequences for third parties. For example, if electronic medical record contains information about persons (relatives, neighbors, co-workers, etc.) who have submitted an application for a psychiatric examination of a patient without his consent, the patient have learned about it in future, may commit aggressive acts against them in case of mental disorder aggravation. Thus, individuals may be harmed as a result of committing by patients with mental disorders any socially dangerous acts violating the rights and interests of others, in case of improper control over patient's access to electronic forms of medical documentation.

Mental health is a very special component of human health, which explains specific features of psychiatric care and the rules of its provision in comparison with the general rules of public health protection, including terms of patient confidentiality, access to medical information and documentation. Thus, according to the Law, in case of mental disorder medical record must contain information, provided to a patient about the nature of mental disorders, aims, methods, including alternatives, and duration of recommended treatment, as well as possible pain, risks, side effects and expected results (second part of Article 11). It must contain also patient's refusal from treatment if it happens (second part of Article 12); an opinion of psychiatrist differ from with the decision of the medical commission (second part of Article 21); psychiatric examination data and conclusion about the mental health status of the subject (part six of article 23); decision on psychiatric examination of persons without their consent or without the consent of their legal representatives (part three of Article 25); a decision on the establishment or termination of follow-up psychiatric supervision (part three of Article 27); consent for hospitalization in hospital providing psychiatric care (part five of Article 28); kind and time of physical restraint or seclusion (second part of Article 30).

However, the Act does not oblige definitely to provide this information for a person suffering from mental disorder in a precisely documented form, establishing the accessible form of information about the nature of mental disorders, methods, including alternative, recommended duration of treatment as well as the possible pain, the risks, side effects and expected results of treatment which must be included in medical records (second part of Article 11).

However, this does not imply limitation of the information providing for a person, especially capable, including a documentary about his mental health or disorder, as well as no restrictions are present on content or amount of documentation provided. These statutes only make the characteristics of the information dependent on interests of the person receiving mental health care, first of all, on his condition, which can be evaluated by the doctor or medical commission. This is not inconsistent with the provisions of the Federal Law «On the basis of the health of citizens in the Russian Federation» (Parts 2 and 3 of Article 22) [13].

However, the third part of Article 5 of the Law directly prohibits the restriction of the rights and freedoms of persons with mental disorders, only on the basis of a psychiatric diagnosis, the fact of being under medical supervision or stay in the mental health care hospital. The legislation does not give grounds to an arbitrary, not determined by the interests of the patient's refusal to grant him medical records, as well as to the unmotivated, groundless restriction of his right to obtain it to the extent in which it is really necessary, unless the 
provision of such information does not harm him or «third parties» [14].

Some electronic records may be hidden from the patient by medical facility CEO's decision as well as by ethical reasons. The responsibility for compliance with the constitutional rights of the patient is assigned in that case to the medical management of the facility [11].

When providing of health information (documents) to a person suffering from a mental disorder is impossible for whatever legal grounds, it can be given to his representative according to the law. Any citizen during provision of mental health care for him has the right to invite a representative of their choice to protect their legitimate rights and interests according to Article 7 of the Act. This can be a lawyer or an employee of the state legal bureau or any other person authorized by state law office to provide free legal assistance. The lawyer has the right, pursuant to subparagraph 1 of paragraph 3 of Article 6 of the Federal Law of May 31, 2002 № 63-FZ «On Advocacy and the Legal Profession in the Russian Federation» [15] to collect information necessary for rendering legal assistance, including query help, specifications and other documents from government, local authorities and public associations and other organizations. These agencies and organizations in accordance with Article 13 of the Federal Law «On the basis of health protection in the Russian Federation» (the Base) in a manner prescribed by law, must give the lawyer requested documents or certified copies, not later than one month from the date of request reception, having written consent of the citizen (patient) or his legal representative [13].

\section{TERMS OF CONFIDENTIAL MEDICAL INFORMATION DELIVERY}

Information about the fact of person's request for health care, the state of his health and diagnosis, and other information obtained during his medical examination and treatment constitute medical secrecy. Disclosure of information constituting a medical secrecy is not allowed, even in the event of patient's death, to persons who possess it in the course of training, performance of job, office and other duties, except cases specified in Paragraphs 3 and 4 of Article 13 of the Bases. Having written consent of the citizen or his legal representative, the information containing a medical secrecy may be disclosed to other citizens, including officials, in purposes of medical examination and treatment of patients, research, publication in scientific journals, education et.al. Providing of information constituting a medical secrecy, without the consent of citizen or his legal representative is possible in the following cases [13]:

- for the purpose of medical examination and treatment of a citizen, who as a result of his condition is not able to express his will, subject to the provisions of paragraph 1 of Part 9 of Article 20;

- the threat of the spread of infectious diseases, mass poisonings and injuries;

- at the request of the inquiry and investigation organizations, the court, in connection with the investigation or trial, at the request of prosecutors in the exercise of prosecutorial supervision, at the request of the correctional system in connection with the execution of criminal penalties and convicted persons supervising.

- to implement the control over the correctional treatment and/or rehabilitation of persons recognized as drug addicts or consuming drugs or psychotropic substances without a prescription by authorized federal executive organizations;

- in the case of medical care to a minor in accordance with paragraph 2 of Part 2 of Article 20, as well as minor under the age specified in Paragraph 2 of Article 54 , to inform one of his parents or other legal representative;

- to inform the law-enforcement organizations about admittance of the patient if there are reasonable grounds to believe that the damage to his health was caused as a result of unlawful actions;

- for the purpose of military medical examination at the request of military recruitment offices, personnel services and military-medical (medical-flight) commissions of federal executive authorities providing military and equal service according to federal law;

- to investigate an accident at work, occupational diseases and accidents with students during their stay in the educational organization;

- for the exchange of information by medical organizations, including the content of medical information systems to provide medical care, taking into account the requirements of the Russian legislation on personal data;

- for the implementation of accounting and control in the system of compulsory social insurance;

- in order to monitor the quality and safety of medical care in accordance with this Federal Law.

Mentioned above national regulations agree to Principles to protect persons with mental illness and to improve mental health care (adopted December 17, 1991 UN General Assembly Resolution 46/119) [16], according to which the patient has a right of access to information in his medical record, which conducted by a psychiatric facility. This right may be restricted in order to prevent serious harm to the health of the patient and the risk to the safety of others. In accordance with domestic law, any such information not given to the patient should be confidentially provided to patient's personal representative or lawyer ; if any such information is not communicated to the patient, he or his lawyer, should be notified of the withholding and the reasons for it. Such decision could be reviewed judicially (paragraph 1 of Principle 19, «Access to Information»).

Federal law dated December 10, 1995 No. 196-FZ «On the Road Safety» [17], providing a compulsory medical examination for driver's license by psychiatrist and expert in 
narcology, in order to identify medical contraindications or limitations to the driving of vehicles, did not establish the obligation of the parties to submit medical records, and places the results of the survey, depending on whether the person concerned shall submit these documents. Thus, patients being on dispensary observation, drop out of sight of psychiatric services when changing residence. The doctors at new patient's residence don't have any information, and if the patient is in remission and has stable clinical symptoms of mental disorder, it becomes possible for him to get a driving license despite the fact that people with certain types of mental disorders can pose danger to life and health of themselves and wider public while driving $[18,19]$. However, if the primary access to electronic documents should be provided for the doctor performing a medical examination, conclusion will become more accurate and reasonable.

\section{EFFECTS OF CONFIDENTIAL MEDICAL INFORMATION DELIVERY OUTSIDE THE LEGAL PROCEEDINGS}

One can face demands of finding a person registered in mental care facilities, coming from the bodies of internal affairs with the wording «because of the perceived need», which, however, stands in flagrant violation since the provision of information constituting a medical secrecy, without the consent of the citizen or his legal representative is permitted at the request of the bodies of inquiry and investigation, the prosecutor and the court in connection only with an investigation or litigation [20]. This refers to the situation where the patient is a party to civil or criminal proceedings. It is important that such information cannot be requested at the stage before a criminal case. The request for information containing medical secrecy must be supported by the facts of procedural checks, criminal case or the criminal and civil legal proceedings.

\section{CASE THAT ILLUSTRATES A PRACTICE CASE OF OUTPATIENT PSYCHIATRIC SERVICES}

Patient K., for the first time himself, voluntarily applied for admission to the mental health care office in 1998 (at age 49), by prescription of the clinic, to obtain the opinion of a psychiatrist for medical and social assessment due to neurological condition. At first he behaved noisy, was convinced that someone from the doctors in the clinic needs to do him « something bad»: «I know, who cares about! I'm not your patient! I want nothing from you». He believed that referral to a psychiatrist, is the machinations of his enemies: «You are connected with them, you are asked to compromise me». Later, when he calmed down and said currently required information for medical report, it became clear that none of his relatives had ever applied to a psychiatrist. K. grew and developed in accordance with the age norm, has higher education, employed in his profession, was married and had no children.

Once while having extreme physical activity in the army, had passed out. He was placed at military hospital with cardiopsychoneurosis. Patient has finished the field service at time after treatment. Since then, our patient felled deterioration of health in the spring and autumn period: recurrent headaches, nosebleeds, blood pressure rises, weakness, heaviness in hands, violation of hands and upper body skin sensitivity.

Mental status of patient described as «circumstantial, sthenic, don't listen to his interlocutor, says about conspiracy among doctors against him without any evidence, dissuasion is impossible. Communication with the psychiatrist considers to be offensive». Psychological examinations showed thinking without qualitative deficiencies, the monotony emotion, mild memory decline, a slight decrease in intellectual abilities, prevalence of schizo-epileptic traits in the personality with the growth of social introversion, and a complete lack of criticism to his condition. While being investigated by medical commission, edge mental pathology has been determined, diagnosis estimate as: organic brain damage with paranoid development of personality.

Patient didn't get treatment at mental health care facility. All records of consulting were included in the medical case report according to established procedure, as well as in special messenger list for medical and social disability expert commission. This list was given to patient unsealed, making possible to familiarize himselve with medical records. Later $\mathrm{K}$. annually within three years voluntarily sought advice from the mental health dispensary for the next re-examination at neurological medical and social disability expert commission, further didn't attending the dispensary.

In 2001, K. addressed to the head of municipal health department demanding to provide a copy of the police request about the fact of his registration at mental health care dispensary, and a copy of the corresponding response. In his statement K. reported that: «there are constant conversations among my neighborhood that I am registered in the mental health care dispensary having a mental disorder. One of my block neighbors, a woman, spreads this information actively».

The outpatient medical record contained a written request addressed by the district police inspector to the CEO of dispensary on the fact of $\mathrm{K}$ 's registration. The district psychiatrist himself alone responsed to police department, as marked in patient's record card: «... responsing to the police department request it was reported that $\mathrm{K}$. has applied to mental health care dispensary, was examined, the diagnosis placed: organic damage of central nervous system with paranoidal personality development». A copy of that response in the medical documentation is missing., The doctor had exceeded its authority giving himself an answer, because all responses to requests shold be checked and certified by the CEO of health care facility. The request did not specify the reason for granting information constituting medical secrecy., So, the doctor has violated existing regulations by illegal medical data message, which nobody asked for.

In accordance with para. 3 of Art. 61, the Federal Law of 22.07.1993 No. 5487-1 «Fundamentals of the legislation of the Russian Federation on health care», legal at that time, the doctor had no reason to respond to a request of the police station, because «provision of information constituting a medical secrecy, without the consent of the citizen or his legal representative, allowed at the request of the bodies of inquiry and investigation, and the court, in connection with the 
investigation or trial» [21]. Persons who received an information constituting medical secrecy in accordance with the law, along with medical and pharmaceutical officers, taking into account the damage caused to citizens, get administrative or criminal responsibility for the disclosure of medical secrecy in accordance with the legislation of the Russian Federation and its subjects.

After checking the case of patient's complaint by chief consultant in psychiatry of the Municipal Department of Health Care it was advised to take appropriate action to the district psychiatrist for unauthorized response to the police department. The doctor, in connection with the dismissal, was not involved in disciplinary responsibility.

In the period from 2001 to $2014 \mathrm{~K}$. repeatedly appealed to various authorities, supervisory organizations, the heads of departments, with written statements to provide him copies of certificates transferred to the police department, medical outpatient records, and to punish personalities guilty of disclosing information about the state of his mental health.

All K.'s appeals were reviewed in the statutory period, comprehensive written answers and clarifications on issue were given for the applicant. An extract from the medical records of outpatient patient was sent to $\mathrm{K}$. by registered letter. The patient was encouraged to apply for information of interest personally to CEO of mental care dispensary, chief consultant in psychiatry, with the possibility to familiarize himself to medical records, and to receive a copy of the medical record in accordance with Art. 31 of the Federal Law from 22.07.1993, the № 5487-1 «Fundamentals of the legislation of the Russian Federation on health care» [21], later, in accordance with Art. 19, p.p. 1,4,5 Art. 22 of the Federal Law of 21.11.2011, № 323-FZ «On the basis of the health of citizens in the Russian Federation» in the period of these regulations. K. refused to visit officials [13].

Stating his refusal to attend mental health care dispensary patient gave reasons for: «I will never go to where a crime was committed secretly against me by persons in medical uniform, as I found out after a considerable period of time! At the time, I believed the doctors has visited mental health facility seeking for documents on non-psychiatric reason and was cruelly and basely deceived. Defamed, ridiculed, humiliated!».

Content of applications suggests that the activities carried by $\mathrm{K}$, had litigious and querulious character, and his statements on non-provided information, were not confirmed. Violations haven't been identified during the prosecutor's study of the correspondence connected to with K.'s appeals.

In 2014, after receiving an official notification of the Ministry of Health on the termination of correspondence, $\mathrm{K}$. called to the head of the mental health dispensary CEO, and arranged a meeting. K. provided a written request «to give him a complete legibly written copy of my medical record with all existing applications (requests and responses), carefully stored in a mental health dispensary, certified by official seal». The requested documentation has been provided to the patient, and it was explained that the account he had never been registered to a dispensary as a person with mental disorders. Later in the conversation K. reported that he feels a huge relief, regretting that had not come earlier and obeyed the lawyers who tried to dissuade him from visit to the dispensary, because of possible negative consequencies.

\section{COMMENTARY TO THE SUBMITTED CASE}

Analyzing the case, first, it must be said that the lack of attention to the legal standards in psychiatric practice (illegal response to the request of police officials) leads to serious consequences, both for the doctors (long-term unproductive correspondence has taken away a lot of time at the various officials) and for patients (This situation has contributed to the formation of overvalued ideas of reference and multi-year correspondence reinforced the productive symptoms of the patient and brought damage to his mental health). The case illustrates the consequences of such violations in psychiatric practice for health care professionals as well as for patients with clinical manifestation of overvalued or delusional ideas of a relationship that in the reported case were supported by the lawyer's activity.

Working with patients with mental disorders is certainly difficult, requires concerted actions of medical staff and the management of mental health care facilities, the internal affairs agencies, prosecutors, lawyers, professional associations of human rights, ethics committees. Providing to patient an access to his electronic medical records remotely without coming to mental health dispensary would accelerate the solution to the conflict, and help to restore the psychological comfort of the patient saving time for officials involved in the conflict.

\section{CONCLUSION}

The efficiency of mental health care delivering may be by more wide usage of IT in order to improve interoperability and continuity in the work of regional mental health facilities, through the development of electronic forms of medical documentation, access to which is determined by regulatory cooperation between all services involved in dealing to patients with mental disorders. The rights and providing of access to patient's electronic medical records should only apply to certain types of records, and some folders should have limited access, if the enclosed information concerns the "third parties". For example, if such documents may contain information about the persons who have submitted an application for a psychiatric examination of somebody without his consent or without the consent of his legal representative.

\section{REFERENCES}

[1] V.A. Kamaev, B.N. Filatov, and D.P. Panchenko, "Multi-module system of medical diagnostics", Journal of Computer and Information Technology, № 1, 2005, pp. 17-19.

[2] N.V. Le, V.A. Kamaev, D.P. Panchenko, and O.A. Trushkina, "A Review of the appoaches to designing medical expert system on differential diagnosis", Proceedings of Volgograd State Technical University, Vol. 20, № 6 (133), 2014, pp. 50-58.

[3] N.A. Salnikova, B.A. Lempert, and M.B. Lempert, "Integration of Methods to Quantify the Quality of Medical Care in the Automated Processing Systems of Medical and Economic Information", 
Communications in Computer and Information Science, Vol. 535. CCIS Volgograd; Russia Federation, 2015, pp. 307-319.

[4] N.V. Le, V.A. Kamaev, and N.P. Sadovnikova, "Formation of knowledge in the medical expert system pre-diagnostics". In: Modern technology and management. Collection of scientific works of the III International Scientific and Practical Conference, VPO Branch of Moscow State University of Technology and Management of $\mathrm{K}$. Razumovsky in the district. n. Bright Yar Volgograd region, 2014, pp. 55-60.

[5] N.V. Le, V.A. Kamaev, D.P. Panchenko, and O.A. Trushkina, "Model Representation of knowledge in the medical expert system of differential diagnosis", Proceedings of Volgograd State Technical University, Vol. 20, № 6 (133), 2014, pp. 41-50.

[6] A.P. Stolbov, and P.P. Kuznetsov, "The integration of personal health data: implementation stages”, Doctor and information technology, № 5, 2011, pp. 31-36.

[7] S.I. Karas, "Web-based tools in medical education and health care", Humanitarian science, Vol. 9, 2015, pp. 141-148.

[8] N.V. Le, and V.A. Kamaev, "The Use of Expert System for Preliminary Remote Diagnostics", Questions of modern science and practice. University name of V.I. Vernadsky, № 2 (56), 2015, pp. 204-209.

[9] L.N. Blagov, and A.A. Loshchinin, "Information Technology in Clinical Psychiatry and Addiction: the potential of innovation”, Narcology, № 12, 2013, pp.88-93.

[10] E.V. Soboleva, and A.V. Grachev, "Experience in the use of information and communication technologies in the outpatient care of psychiatric services Astrakhan region", In the book: XVI Congress of Psychiatrists Russia, 2015, pp. 168-169.

[11] B.D. Tsygankov, and V.A. Yevtushenko, "Making and keeping medical records in a psychiatric hospital”, M. MSMSU, 2012, pp. 276.

[12] Law of the Russian Federation of July 2, 1992 № 3185-1 “On psychiatric care and guarantees of citizens' rights in its provision", SPS Consultant Plus, Bulletin of the Congress of People's Deputies of the Russian Federation and the Supreme Soviet of the Russian Federation dated August 20, 1992 № 33. Art. 1913.
[13] Federal Law of 21 November 2011, № 323-FZ “On the basis of health protection in the Russian Federation", art. 22, Text to claim 5 of the Federal Law published in "Rossiyskaya Gazeta" dated November 23, 2011 № 263.

[14] Determination of the Constitutional Court on July 2, 2015 № 1544-O "According to the complaint of a citizen Alexander V. Trofimov, a violation of his constitutional rights situation of the second part of Article 5 of the Law "On psychiatric care and guarantees of citizens' rights in its provision", [Electronic resource], System GARANT: http://base.garant.ru/71140866/\#ixzz3t0Xino2N. Date 11.30 .15 treatment.

[15] Federal Law of May 31, 2002 № 63-FZ “On Advocacy and the Legal Profession in the Russian Federation", Meeting of the legislation of the Russian Federation on June 10, 2002 № 23. Art. 2102.

[16] Resolution of the UN General Assembly on December 17, 1991 № 46/119 "Protection of Persons with Mental Illness and the improvement of mental health care", [Electronic resource], Portal GARANT.RU: http://base.garant.ru/2565323/. Date 11.30.15 treatment.

[17] Federal law of December 10, 1995 № 196-FZ “On the Road Safety”, Meeting of the legislation of the Russian Federation dated December 11, 1995, № 50, Art. 4873.

[18] O.V. Poplavskaya, "Problems receiving targeted reference information about the patients, the dispensary observation in the IPA", Testing, №6 (21), 2014, pp.105-107.

[19] N.Y. Orudjev, O.V. Poplavskaya, and N.A. Chernaya, "Organizational and legal problems of mental health care", In: Proceedings of the scientific conference of the faculty staff, dedicated to the 80th anniversary of Volgograd State Medical University, 2015, pp. 78-80.

[20] Yu. Argunova, "Inform, means protected”, “Ariadne's thread”, № 7 (98), 2014, pp.6.

[21] Federal Law of 22.07.1993 № 5487-1 "Fundamentals of the legislation of the Russian Federation on health care", Meeting of the legislation of the Russian Federation dated November 28, 2011 № 48 Art. 6724. 